\title{
A systematic and holistic approach leads to surgery followed with chemotherapy and palliative radiation in a locally advanced case of squamous cell carcinoma of gluteal region
}

\author{
Shwetima Chaudhary*, Rashmi Gupta and Rajendra Kumar \\ Department of Radiotherapy, King George's Medical University, Lucknow UP, India
}

\begin{abstract}
Introduction: Squamous Cell Carcinoma of gluteal region is not more oftenly seen, requires a conventional treatment to remove the magnitude of the disease with combined modalities of treatment.

Presentation of the case: Here a case of 58-year-old male from Bihar state (India) presented with history of large ulcer proliferative lesion in the gluteal region from last 8 months, which was progressively increasing in size due to inadequate treatment.

Discussion: Biopsy has been retrieved. Due to large volume of disease, treatment started with chemotherapy followed by palliative radiation then considered for surgery. We observed regression of magnitude of disease on subsequent follow up and improvement in the quality of life.

Conclusion: Clinicians must know the possibility of tumor of the gluteal region especially in the remote areas and they must be treated conventionally with combined modalities to improve the overall survival.
\end{abstract}

\section{Introduction}

About 2 out of 10 skin cancers are squamous cell carcinomas (also called squamous cell cancers). The cells in these cancers look like abnormal versions of the squamous cells seen in the outer layers of the skin. These cancers commonly appear on sun-exposed areas of the body such as the face, ears, neck, lips, and backs of the hands. They can also develop in scars or chronic skin sores elsewhere. Less often, they form in the skin of the genital area [1]. Squamous cell cancers are more likely to grow into deeper layers of skin and spread to other parts of the body than basal cell cancers, although this is still uncommon. Squamous Cell Carcinoma (SCC) is the most common type of skin tumor with the ability of metastatic. It represents about $20 \%$ of all malignancies diagnosed worldwide each year. Despite increased knowledge regarding the causes of skin cancer, the incidence of SCC rises. The disease originates from epidermal keratinocytes. It is prevalent in men and increases with age [2].

\section{Case presentation}

We are reporting a case of 58 years old male who hails from eastern part of India presented with history of small lump in the buttocks for 8 months, which was increasing in size and burst out with foul smelling pus discharge from the lesion and also unable to stand straight and walk. In remote areas the lesion was being treated as an infection and symptomatic treatment was also taken for pain relief and local wound dressing done at few intervals in local hospital or by patient's attendants. Patient consulted a private hospital where an FNAC was done from the lesion s/o dysplastic mesenchymal tissue for which excision was for biopsy from the ulcerated side which revealed well differentiated squamous cell carcinoma [3,4]. The case presented to us in the outpatient department with these complaints and reports of biopsy. Initial size of the lesion over the buttock is $12 \times 8 \mathrm{~cm}$ ulcer proliferative type associated with foul smelling pus discharge and also associated with bleeding (Figure 1). The patient was admitted with above complaints, with all the relevant investigation. Treatment was planned as systemic chemotherapy and palliative radiation (hypo fractionation) to lower down the bulk of the disease and to make patient relief from pain. Patient has also undergone for surgical debridement for removal of slough and wound cleaning and dressing from General Surgery department Patient was on regular follow up and came in every three weeks for the chemotherapy cycles. Initially after giving three cycles of chemotherapy, patient was planned for palliative radiation $(15 \mathrm{gy} / 3$ fraction), we assessed the patient on the basis of clinical examination and patient's subjective response to pain and regression of disease [5]. We assessed the patient after 2 months of palliative radiation to the local site through the clinical examination which revealed that wound size has reduced to $6 \times 5 \mathrm{~cm}$ (in comparison of $12 \times 8 \mathrm{~cm}$ at initial) ulcer with yellowish slough present over the buttock, margins are clearly defined with rolled out edges (Figure 2). We can clearly appreciate the reduction of disease with neovascularization in and around the site.

${ }^{*}$ Correspondence to: Shwetima Chaudhary, Department of Radiotherapy, King George’s Medical University, Lucknow UP, India, E-mail: swm222@gmail.com

Key words: squamous cell carcinoma, gluteal region, chemotherapy, palliative radiation, surgery

Received: May 13, 2019;; Accepted: June 04, 2019;; Published: June 07, 2019 
Patient's general condition and quality of life was also improved in terms of no pain, easiness in routine activities and mobilization. These events took place simultaneously as there was no gap in the treatment and patient was given total six cycles of chemotherapy followed by opinion from surgical oncology department for surgical assessment where patient has been assessed through the MRI Scan pelvis and other metastatic work-up. After this patient was considered fit for surgery and underwent Wide Local Excision with V-Y advancement with the collaboration of Surgical Oncology and Plastic Surgery. Patient post-operative status was uneventful, and patient is mobile with no any other complications.

\section{Investigation}

As per the surgical oncology Opinion patient was considered operable and underwent for Investigations beside General physical examination, performance status, central nervous examination, gastrointestinal tract examination, respiratory function test and cardiovascular examination followed with Pre-Anesthetic Check-up (PAC) (Figure 3).

\section{Chest X-ray PA view-shows normal study}

MRI pelvis reported an ill-defined ulcerative lesion of size $4 \times 3.5 \times 4.8 \mathrm{~cm}$ displaying signal intensity alteration with heterogeneous post contrast enhancement is seen involving gluteal cleft more towards right side. It is infiltrating adjacent part of bilateral gluteus maximus muscle [6]. Anteriorly it was reaching up to the cortex of the coccyx. Few lymph nodes were seen in bilateral inguinal and external iliac region with short axis diameter up to $1.5 \mathrm{~cm}$ (Figure $4 \& 5$ ).

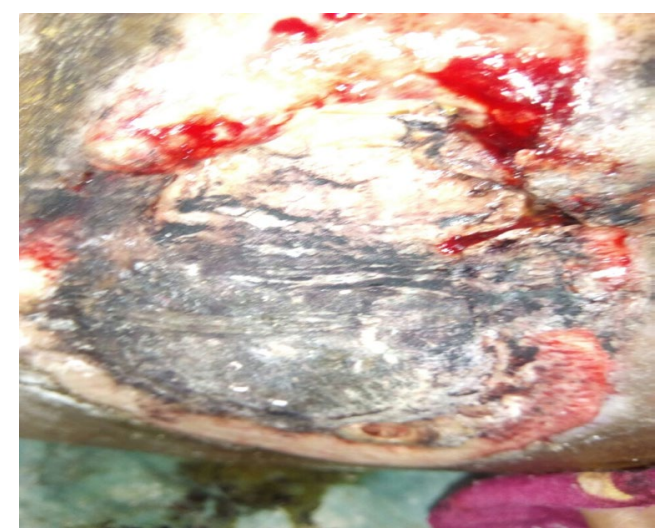

Figure 1. Initial figure of the wound over the buttock, with extensive and large size ulcer proliferative mass with pus discharge and bleeding

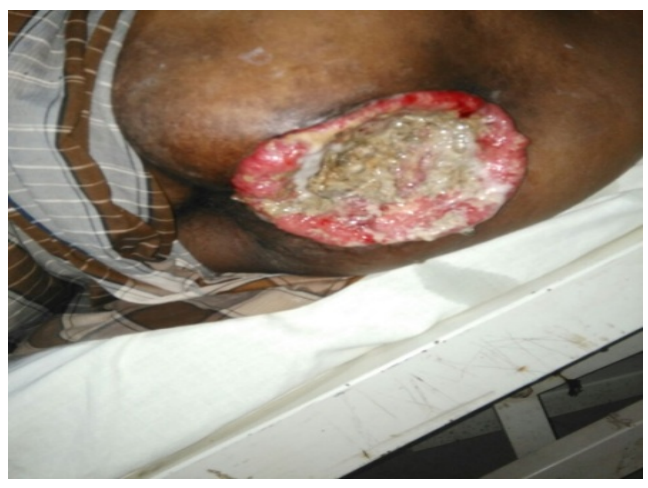

Figure 2. Large Size wound over the buttock, after 3 cycle of chemotherapy

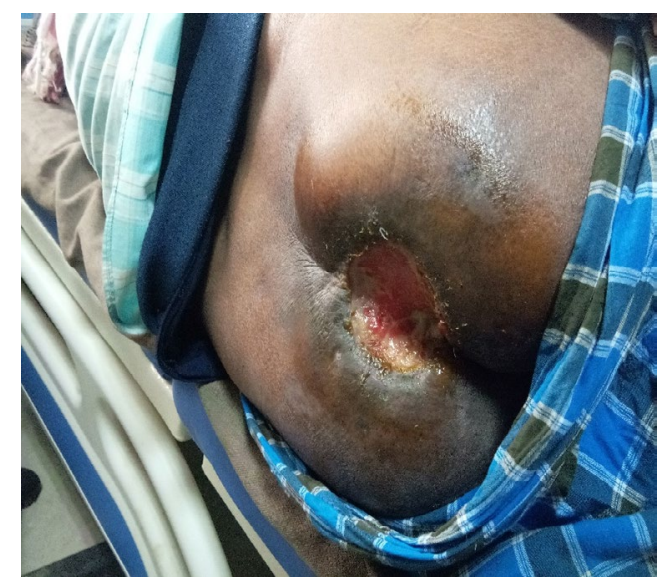

Figure 3. Showing response of Palliative RT, reduction in the size of the wound and margins are inverting and rolling with neovascularization

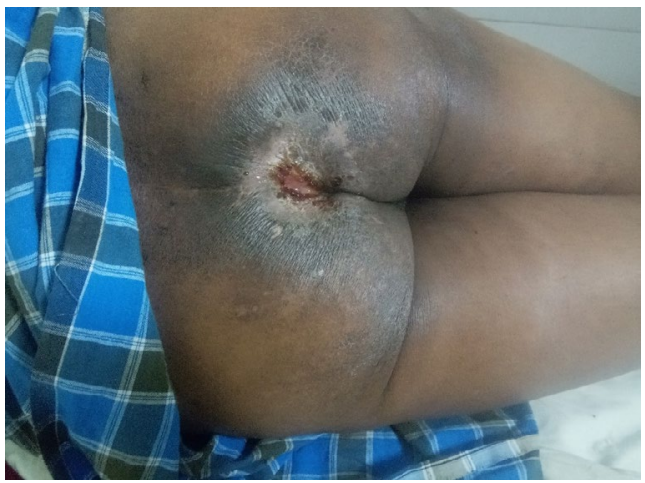

Figure 4. Showing effect of Chemo-radiation in more reduction in the size of the wound, the margins are also clearly defined

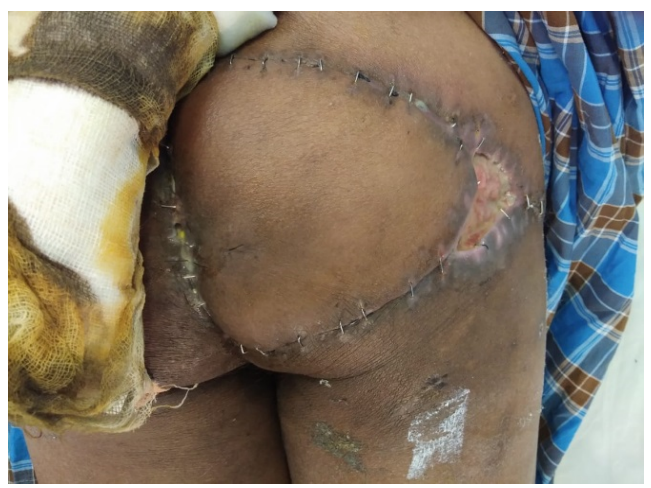

Figure 5. Showing flap reconstruction, healed up margins after surgery

Blood investigations-complete blood count, liver function test, kidney function test, viral markers, bleeding and clotting time, PT/ INR [7].

\section{Treatment}

In the present case, the patient was initially diagnosed with squamous cell carcinoma of gluteal region and treated with chemotherapy, palliative radiation and surgical excision followed with plastic reconstruction with preservation of function and satisfactory cosmetic results [8]. 


\section{Discussion}

Patient was on regular follow-up, till now is 20 months without any metastasis, patient is now able to walk on his own limbs. Outcome of the combined modality treatment policy led to improvement in the quality of life and overall survival, as well as the performance status in the patient.

\section{Conclusion}

Squamous cell carcinoma of the gluteal region is to be dealt with proper care especially in remote areas where patients are ignorant about their status of the disease and its output. Patient should be well counselled regarding the disease and other comorbidities. Treatment should be well defined as of radiation dosing and its effects, palliation and methodical surgery along with the results of subsequent follow up in order to procure a better quality of life.

Tumor at gluteal region should be examined and investigated properly.

Genital hygiene and wound care should be proper along with General surgery opinion.

Early initiation of treatment led to complete recovery.

\section{References}

1. Chatzis I, Noussios G, Katsourakis A, Chatzitheoklitos E (2009) Squamous cell carcinoma related to long standing pilonidal-disease. Eur J Dermatol 19: 408-409.

2. Sharma D, Pratap A, Ghosh A, Shukla VK (2009) Malignant transformation of a pilonidal sinus. Surgery 145: 243-244. [Crossref]

3. Glover DM, Kiehn CL (1949) Marjolin's ulcer; a preventable threat to function and life. Am J Surg 78: 772-780. [Crossref]

4. Bailey \& Love's Short Practice of Surgery (2013) Edited by Norman S Williams, Christopher J K Bulstrode \& P Ronan O'Connell. 26th edition, CRC press Taylor \& Francis group Boca Raton London New York, 593-594.

5. Trent JT, Kirsner RS (2003) Wounds and malignancy. Adv Skin Wound Care 16: 31-34. [Crossref]

6. Lal S, Bain J, Singh AK, Shukla Saree Cancer PK (2012) The Malignant changes in chronic irritation. Journal of clinical and diagnostic research.

7. Copcu E, Aktas A, Sismant N, Oztan Y (2003) Thirty-one cases of Marjolin's ulcer Clinical and Experimental Dermatology 28: 138-141.

8. Wong TH, Khoo AK, Tan PH, Ong BH (2000) Squamous cell carcinoma arising in a cutaneous epidermal cyst. Ann Acad Med Singapore 29: 757-759. [Crossref]

Copyright: $@ 2019$ Chaudhary S. This is an open-access article distributed under the terms of the Creative Commons Attribution License, which permits unrestricted use, distribution, and reproduction in any medium, provided the original author and source are credited. 